Thorax (1970), 25, 382.

\title{
A solitary amyloid nodule in the lung
}

\author{
M. RAY CHAUDHURI and D. J . PARKER \\ The London Chest Hospital, London, E.2
}

\begin{abstract}
Solitary primary amyloid nodule of the lung is rare. Only eight cases have been reported. Our patient was a 66-year-old retired furnaceman who had an asymptomatic, smooth, round shadow in the right lower lobe, discovered acoidentally on routine chest radiography. Right lower lobectomy was performed and a firm round nodule was found in the lateral basal segment. Its cut surface had a yellow-grey tinge and stained mahogany brown with Lugol's iodine. Microscopically the nodule consisted of uniformly eosinophilic-staining material with scattered multinucleate giant cells and groups of lymphocytes, plasma cells, and mononuclear cells at the edge. As the material stained with Congo red and gave typical greenish birefringence under polarized light it was evidently amyloid.
\end{abstract}

Primary amyloid lesions may occur in the lung parenchyma or in the bronchi. The rarest form of amyloid disease of the lung is primary isolated nodular amyloidosis of the parenchyma. The first case was reported by Lesser in 1877 and from then up to 1966 only seven solitary amyloid 'tumours' and 22 cases of multiple nodules were reponted. They were reviewed by Firestone and Joison (1966). Hayes and Bernhardt (1969) reported the eighth case of solitary amyloid nodule of the lung. They kept the patient, a 59-year-old negro man, under constant observation for six years after removing the lesion, and during this time no evidence of any chronic respiratory disease, dysproteinaemia, malignancy or systemic amyloidosis emerged. The condition was therefore regarded as primary.

Because of its extreme rarity, we are reporting this case of solitary amyloid nodule in the lung. The case was unusual for its association with asbestos bodies though no asbestosis was found in the portion of lung removed.

\section{CASE REPORT}

J.H.W., a 66-year-old retired furnaceman, who had smoked five cigarettes a day for well over 20 years, was referred for investigation of a shadow in the right lower lobe (Fig. 1) which had been found on routine chest nadiography two months after a total cystectomy.

In June 1965 the patient complained of haematuria and cystoscopic biopsy revealed a papillary carcinoma of low-grade malignancy. The tumour was treated initially by local diathermy and subsequently by deep $x$-ray therapy. The haematuria recurred and it was considered to be due to irradiation cystitis. In May 1969 an ileal loop bladder was formed and in September 1969 total cystectomy was carried out. Histological examination showed chronic destructive cystitis with radionecrosis but no evidence of malignancy. On examination his general condition was good. The patient denied any cough, dyspnoea or haemoptysis. There was no anaemia and no enlargement of the liver, spleen, lymph nodes, heart or tongue. Both lungs had good air entry with bilateral vesicular breath sounds. The chest radiograph showed a smooth, round shadow in the lateral basal segment of the right lower lobe, confirmed on tomography. Neoplastic cells were not found in the sputum though all specimens (total of three) contained asbestos bodies.

At operation in October 1969, a nodule, approximately $3 \mathrm{~cm}$. in diameter, was found subpleurally in the lateral basal segment of the right lower lobe. It was mobile within the substance of the lung, but the pleura overlying it was puckered. A routine dissection right lower lobectomy was carried out. The remainder of the lung was healthy.

SURGICAL SPECIMEN There was a round nodule, 2.5 $\mathrm{cm}$. in diameter, in the lateral basal segment (Fig. 2) encroaching on the pleura laterally. The pleura was thickened and covered by adhesions. The nodule was very firm and its cut surface had a yellow-grey tinge with flecks of black pigment. It tended to shell out of the surrounding lung. The rest of the lobe was normal. The nodule stained red with Congo red and mahogany brown with Lugol's iodine.

Microscopically the nodule consisted of uniformly eosinophilic staining material, virtually structureless except near the edge, where traces of a laminar pattern were found. In some areas it had a flecked appearance (Fig. 3) and in other regions it formed parallel or concentric layers. Near the edge of the 
FIG. 1. Chest radiograph showing a smooth round shadow in the lateral basal segment of the right lower lobe.

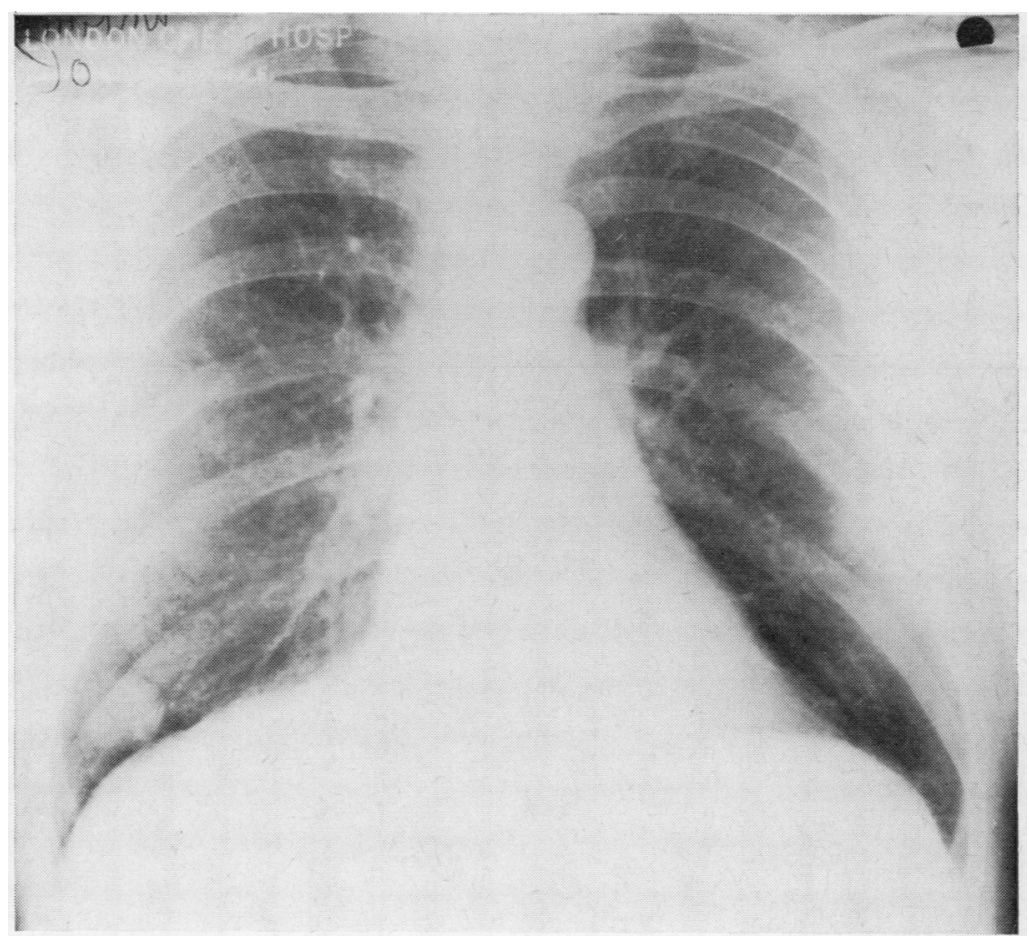

nodule, cuboidal metaplasia of the alveoli was associated with scattered multinucleate giant cells (Fig. 4) which appeared to be engulfing the eosinophilic material. Groups of lymphocytes and plasma cells together with mononuclear cells were found in the clefts near the edge of the nodule. Similar eosinophilic material was present in the walls of the small muscular pulmonary arteries (Fig. 5) near the tumour. The material demonstrated metachromasia with crystal violet, stained with Congo red and gave greenish birefringence under polarized light, and showed bright yellow fluorescence against an olivegreen background (Cooper, 1969). The material was thus evidently amyloid.

The rest of the lung tissue was unremarkable apart from the presence of fairly numerous asbestos bodies (Fig. 6), a relic of his days as a furnaceman. There was no asbestosis and no evidence of neoplasm.

The patient was well post-operatively, and the wound healed perfectly without any complications. The serum proteins were normal on quantitative estimation and electrophoresis, and rectal biopsy did not reveal any deposition of amyloid.

FIG. 2. The specimen showing a nodule, $2.5 \mathrm{~cm}$. in diameter, in the lateral basal segment of the right lower lobe. 


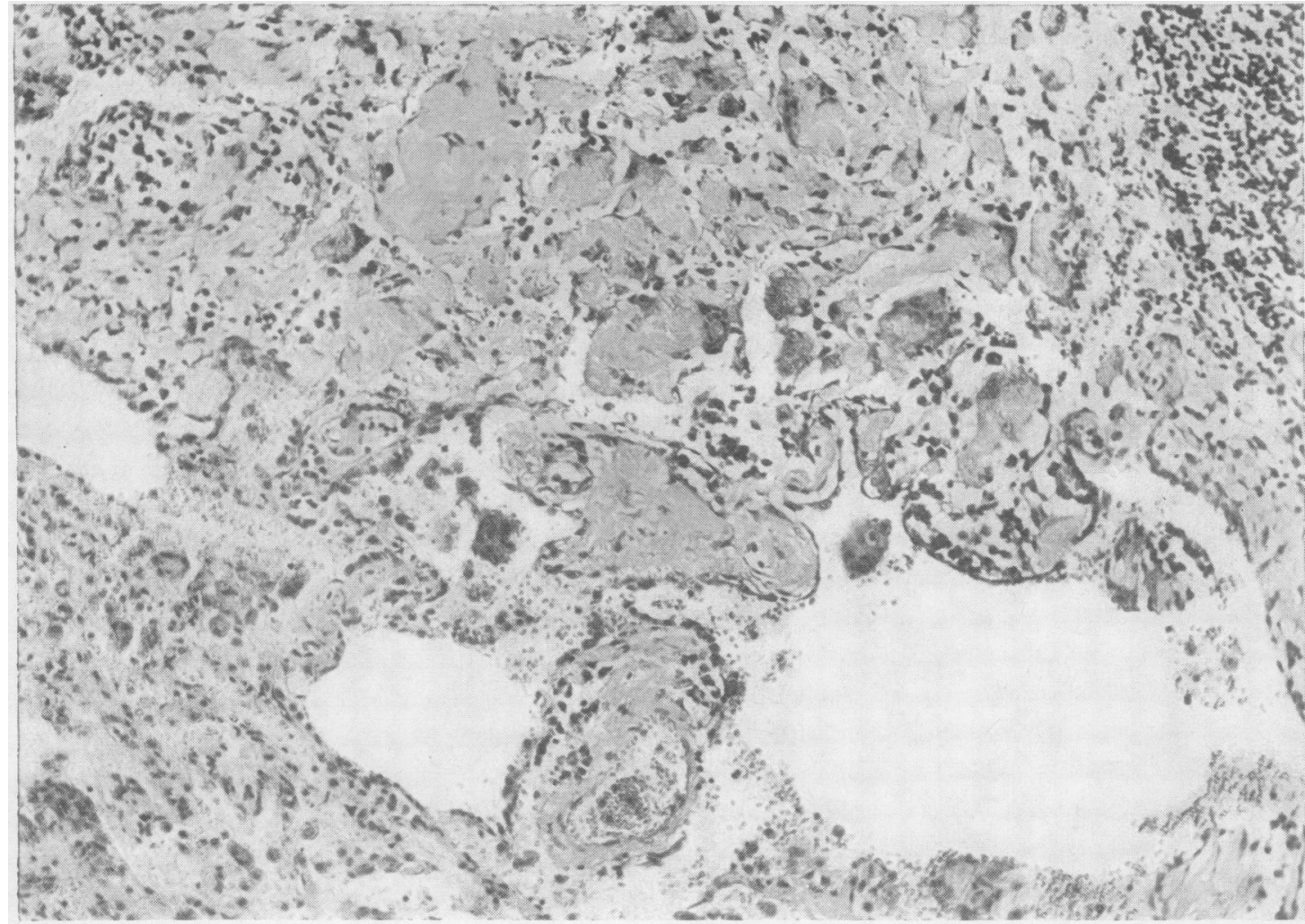

FIG. 3. A section from the edge of the amyloid nodule. Structureless amyloid material is extending into the lung parenchyma with deposition in the alveoli having a flecked appearance. Haematoxylin and eosin $\times 150$.

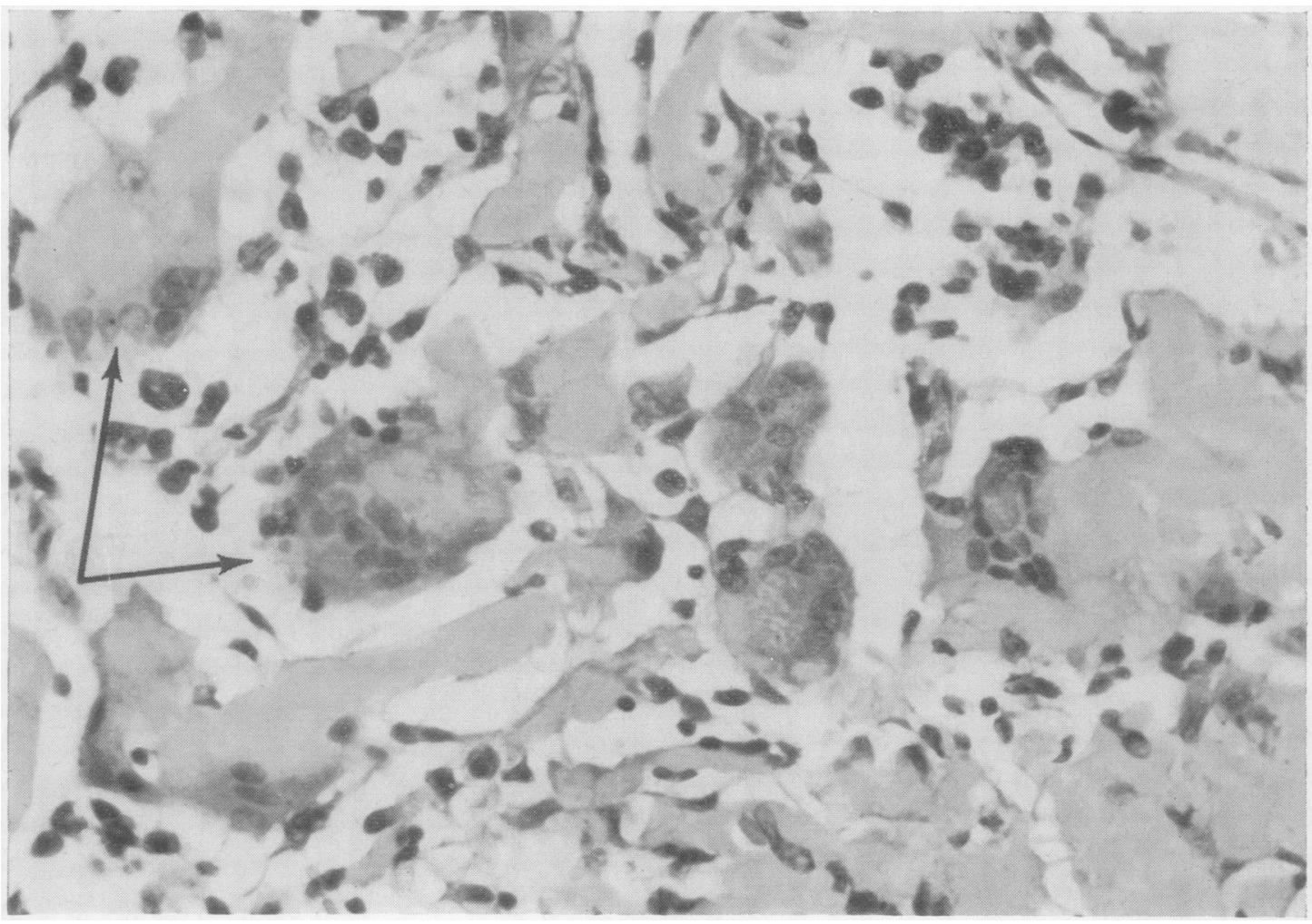

FIG. 4. Another section from the edge of the nodule showing giant cell reaction. Congo red stain $\times 455$. 


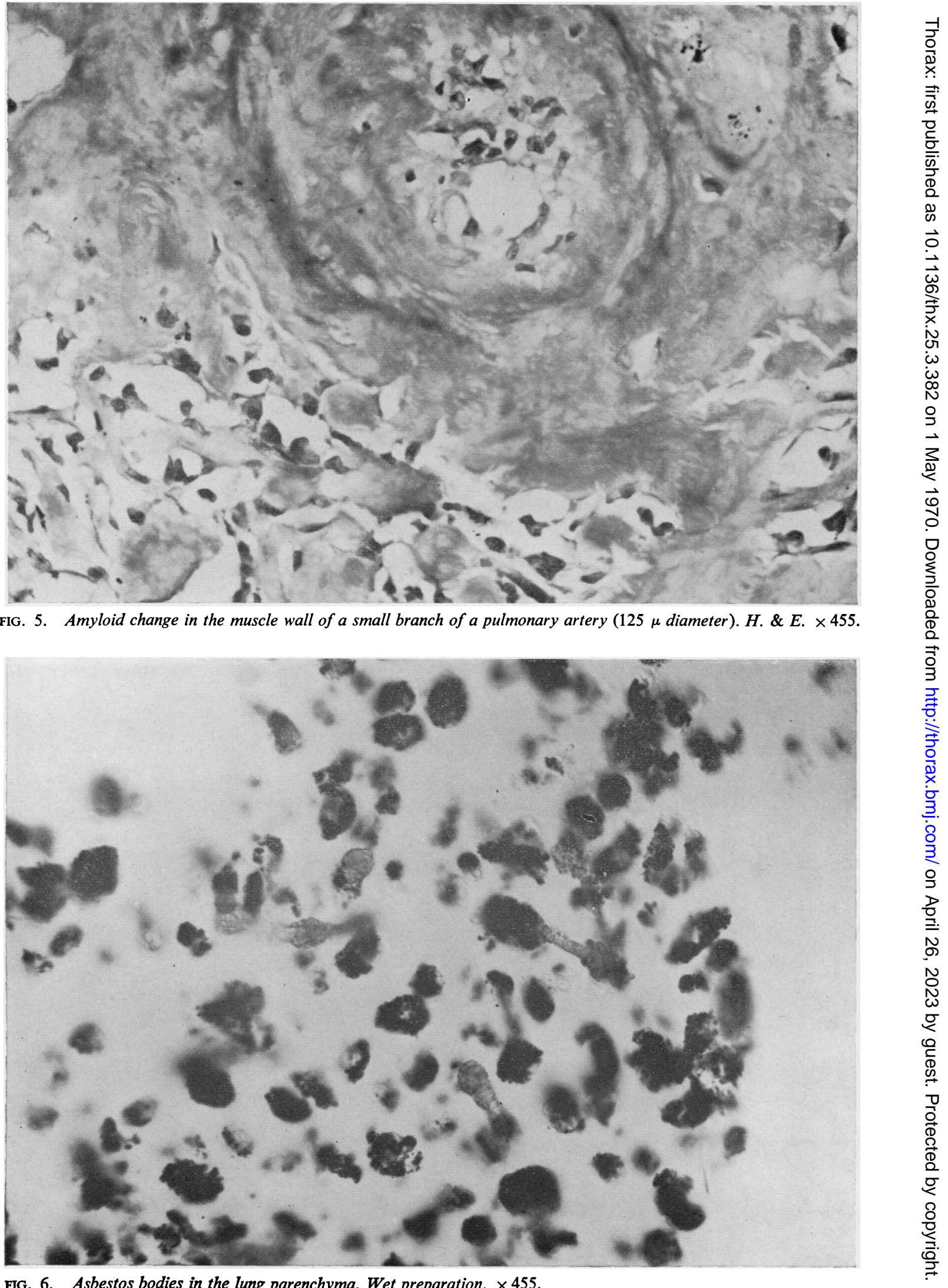

FIG. 6. Asbestos bodies in the lung parenchyma. Wet preparation. $\times 455$. 


\section{DISCUSSION}

Localized parenchymal deposits of amyloid in the lung may be single or multiple. They are usually symptomless, and are discovered accidentally on routine chest radiography (as in our case) or at necropsy. They have no relation to, and exist independently of, bronchial deposits; their size varies from 2 to $15 \mathrm{~cm}$., and they may occur at any age and in either sex. They may be found in any lobe of the lung, but they are always subpleural and adjacent to pulmonary vessels and bronchi, and have the usual translucent greyish appearance of amyloid tissue elsewhere. Most of these nodules show calcification, cartilage formation or even ossification. As these lesions are so rare and as they lack any distinctive clinical or radiological features, they inevitably defy preoperative diagnosis. They are also characterized by non-involvement of organs outside the lung. The benign, chronic nature of these lesions is emphasized by radiographic evidence of their existence for as long as a decade prior to diagnosis, as happened in the cases of Firestone and Joison (1966).

Microscopically the deposits are found beneath the pleural surface. As they enlarge they infiltrate the lung tissue without displacing it and involve alveolar walls and even small bronchi. At their edges they are surrounded by plasma cells, lymphocytes, and occasional foreign-body giant cells which may contain ingested amyloid.

Their cause is not known. Weiss (1960) thought that isolated nodular amyloidosis might result from a localized Arthus phenomenon, and Prowse and Elliott (1963) conjectured that continuous stimulation by a local source of antigen, as may occur in chronic bronchial disorders such as chronic bronchitis and bronchiectasis, might lead to deposition of amyloid. However, there is no evidence that antigen-antibody reactions or chronic bronchial inflammations produce amyloidosis of the lung. Diffuse or isolated amyloid in the lung never occurs in long-standing chronic bronchitis, bronchiectasis, lung abscess or even diffuse collagen diseases.

We are indebted to Dr. N. L. Rusby, visiting physician, and Mr. V. C. Thompson, visiting surgeon, London Ohest Hospital, for allowing us to publish their case. We are also indebted to Dr. K. F. W. Hinson, Director of Pathology, Hospitals for Diseases of the Chest, and Dr. D. P. Winstanley, consultant pathologist, London Chest Hospital, for their advice and criticism. Our thanks are also due to Mr. K. G. Moreman, Chester Beatty Institute, and Mr. V. Jones, London Chest Hospital, for photography and technical assistance.

\section{REFERENCES}

Cooper, J. H. (1969). An evaluation of current methods for the diagnostic histochemistry of amyloid. J. clin. Path., 22, 410. Firestone, F. N., and Joison, J. (1966). Amyloidosis, a cause of primary tumors of the lung. J. thorac. cardiovasc. Surg., 51, 292.

Hayes, W. T., and Bernhardt, H. (1969). Solitary amyloid mass of the lung with 6-year follow-up. Report of a case. Cancer (Philad.), 24, 820 .

Lesser, A. (1877). Ein Fall von Enchondroma osteoides mixtum der Lunge mit partieller Amyloidentartung. Virchows Arch. Path. Anat., 69, 404.

Prowse, C. B., and Elliott, R. I. K. (1963). Diffuse tracheo-bronchial amyloidosis; a rare variant of a protean disease. Thorax, 18, 326.

Weiss, L. (1960). Isolated multiple nodular pulmonary amyloidosis. Amer. J. clin. Path., 33, 318. 